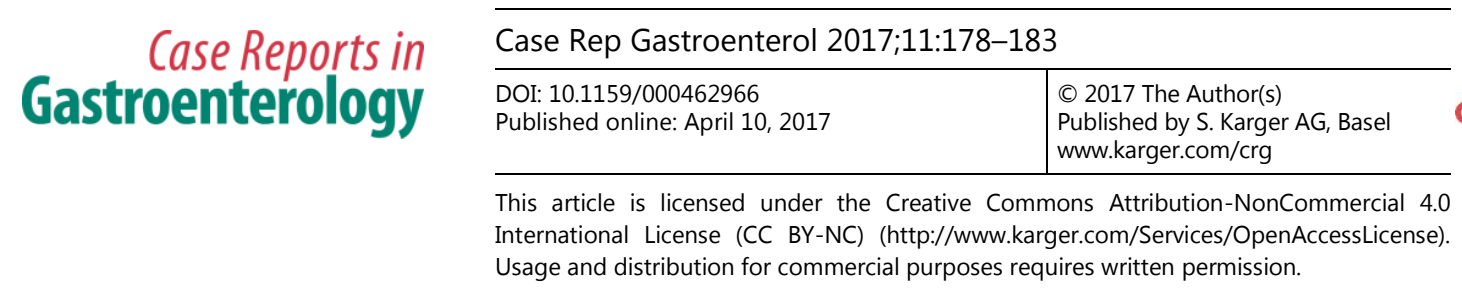

\title{
Cystic Lymphangioma of the Colon: Endoscopic Removal beyond the Frontiers of Size
}

\author{
Kanthi Rekha Badipatla Chaitanya Chandrala Puvanalingam Ayyadurai \\ Madhavi Biyyam Binita Sapkota Masooma Niazi \\ Suresh Kumar Nayudu \\ Bronx Lebanon Hospital Center, Bronx, NY, USA
}

\section{Keywords}

Cystic lymphangioma $\cdot$ Endoscopic resection · Lesion size

\begin{abstract}
Cystic lymphangiomas are benign colonic neoplasms arising from the submucosa. Traditionally, endoscopic resection has been described for smaller lesions, while surgery is reserved for larger symptomatic lesions. We present a case of a 69-year-old asymptomatic individual noted to have a cystic lymphangioma of the colon measuring $5 \mathrm{~cm}$, which was successfully removed with endoloop endoscopic resection without any complications.
\end{abstract}

(C) 2017 The Author(s)

Published by S. Karger AG, Basel

\section{Introduction}

Cystic lymphangiomas are unusual nonmalignant lesions, which result from failure of lymphatic channels to communicate with the main lymphatic system during embryological development [1]. These lesions are mostly seen in the head and neck region. Histologically, they may have single or multiple locules containing liquid contents [1]. In addition, these lesions are lined with a single layer of endothelium like any vascular lesion [1]. The lesions are located anywhere in the body with the abdomen being an uncommon location. 


\section{Case Reports in Gastroenterology}

Case Rep Gastroenterol 2017;11:178-183 DOI: $10.1159 / 000462966$ (c) 2017 The Author(s). Published by S. Karger AG, Basel www.karger.com/crg

Badipatla et al:: Cystic Lymphangioma of the Colon: Endoscopic Removal beyond the Frontiers of Size

Cystic lymphangiomas of the colon are uncommon, with the potential to grow to a large size. These lesions have been increasingly reported lately with more colonoscopies being performed in the current era for various indications. In this current situation, it becomes imperative for general physicians and gastroenterologists to know how to manage these lesions. Various imaging modalities including computed tomography, magnetic resonance imaging, and, more recently, endoscopic ultrasound, are being used to diagnose and assess the extent of lesions prior to therapeutic intervention [2].

Conventionally, endoscopic removal has been done for smaller-sized lesions, while larger ones are commonly treated with surgical interventions. However, based on the clinical presentation and locations, various treatment options including minimally invasive and open surgical interventions are being employed [3].

Our case exemplifies that with the advancement of therapeutic endoscopy, larger lesions can be successfully removed with endoscopic interventions.

\section{Case Presentation}

A 69-year-old male was referred to the gastroenterology clinic for screening colonoscopy. Upon the initial interview, he denied abdominal pain, nausea, vomiting, or change in bowel habit. There was no reported history of gastrointestinal bleeding. His appetite was good with stable weight. His medical comorbidities included bronchial asthma, hypertension, type II diabetes mellitus, and gout. On a further interview, he reported that he underwent cholecystectomy in the past. He denied smoking, alcohol consumption, and recreational drugs. His family history was noncontributory for any gastrointestinal malignancies.

At the time of the initial visit, his vital signs were within normal limits. Cardiopulmonary and neurological examinations were within normal limits. There was no distension or visible mass upon inspection of the abdomen. Bowel sounds were normoactive on auscultation. The abdomen was soft and nontender with no organomegaly on palpation. There were no signs of intra-abdominal free fluid on percussion.

Laboratory parameters showed a hemoglobin level of $12.6 \mathrm{~g} / \mathrm{dL}$, hematocrit 39.3\%, white blood cell count of $7.3 \mathrm{~K} / \mu \mathrm{L}$ and platelets of $218 \mathrm{~K} / \mu \mathrm{L}$. His electrolytes and liver function tests were normal. His blood urea nitrogen and creatinine were $24 \mathrm{mg} / \mathrm{dL}$ and $2 \mathrm{mg} / \mathrm{dL}$, respectively.

Flexible colonoscopy was performed under monitored anesthesia care. During colonoscopy, a large glossy polypoid lesion in the right colon was noted. Biopsies of the lesion were done, which were nondiagnostic. Given the large size of the lesion and the inconclusive biopsy, we decided to proceed with repeat colonoscopy. The patient underwent repeat colonoscopy, which revealed a 50-mm polyp (Fig. 1) in the ascending colon. It was successfully removed using an endoloop placement and hot snare polypectomy (Fig. 2). Although no immediate bleeding was noted, prophylactic endoscopic hemoclips were deployed at the site to close the defect and to prevent delayed bleeding. Histopathological examination showed polypoid colonic tissue with markedly dilated spaces, lined by a single layer of thin endothelial cells predominantly in the submucosa with overlying normal colonic mucosa, consistent with cystic lymphangioma of the colon (Fig. 3). Cauterized margins were free of lymphatic tissue involvement. 


\section{Case Reports in Gastroenterology}

Case Rep Gastroenterol 2017;11:178-183 DOI: 10.1159/000462966 (c) 2017 The Author(s). Published by S. Karger AG, Basel www.karger.com/crg

Badipatla et al.: Cystic Lymphangioma of the Colon: Endoscopic Removal beyond the Frontiers of Size

\section{Discussion}

Lymphangiomas are uncommon, benign tumors arising from lymphatics involving various parts of the body [4]. The most common location is usually the head and neck, with 5\% of all lesions occurring in the abdominal cavity [2] and with the colon also being one of the reported locations.

The mean age of diagnosis is reported as 52 years with no gender preponderance [5]. The right colon seems to be a more common site than the left colon [5]. The symptomatology spectrum ranges from asymptomatic presentation detected on routine colonoscopy to bleeding and alteration in bowel habit or pain [6]. There have also been reported cases of intussusception $[7,8]$.

Colonic cystic lymphangiomas appear as smooth sessile or pedunculated lesions noted on white light endoscopy. They are usually solitary lesions but rarely present as lymphangiomyomatosis with multiple lesions. Biopsy with cold forceps may not be yielding given the submucosal location of the lesion as in our case. The literature also suggests a role of endoscopic ultrasound in the diagnosis, where these lesions appear as anechoic, septate, and submucosal [2]. Fine-needle aspiration of the lesions may show paucity of cells [9].

There is also a school of thought that if the typical endosonography confirms the diagnosis of cystic lymphangioma based on the characteristic features, these lesions may not need treatment. This holds good if the lesions are small and asymptomatic [10]. Given that larger lesions have the propensity to lead to acute complications, endoscopic or surgical treatment should generally be considered.

Endoscopic removal of lesions described in the literature so far has been done for lesions ranging to a maximum measurement of $2-3.5 \mathrm{~cm}$ [11]. Use of a ligating device for removal and unroofing are among the various techniques described for the successful removal [12] of smaller lesions.

Although cystic lymphangiomas of the colon are among the uncommon, benign tumors of the colon, the increase in the reported incidence may parallel the increased use of routine screening colonoscopy. In this setting, we believe that gastroenterologists should be aware of such differentials, workup, and management options. We herein report a case of colonic cystic lymphangioma of a size of $5 \mathrm{~cm}$ that was successfully managed by endoloop endoscopic resection. Previously, endoscopic resection has been attempted for smaller lesions, and so far, we are not aware of such gigantic lesions being removed endoscopically. Endoscopic therapy is associated with less morbidity, lower healthcare costs, and better utilization of resources. This may be a good starting point prior to surgical evaluation. Operative intervention is still the option for lesions that cannot be removed endoscopically and for lesions that present with acute gastroenterological complications. Our case opens doors to an undiscovered option of potential endoscopic intervention for these larger colonic lesions.

\section{Statement of Ethics}

All procedures performed in studies involving human participants were in accordance with the ethical standards of the Institutional Research Board, Bronx Lebanon Hospital Center, Bronx, NY, USA. 


\section{Gastroenterology}

(C) 2017 The Author(s). Published by S. Karger AG, Basel www.karger.com/crg

Badipatla et al.: Cystic Lymphangioma of the Colon: Endoscopic Removal beyond the Frontiers of Size

\section{Disclosure Statement}

The authors declare that they have no conflicts of interest.

\section{References}

1 Yang DM, Jung DH, Kim H, et al: Retroperitoneal cystic masses: CT, clinical, and pathologic findings and literature review. Radiographics 2004;24:1353-1365.

-2 Gottlieb K, Elkharwily A: Endoscopic ultrasound evaluation of a cystic lymphangioma of the colon. J Ultrasound Med 2007;26:1803-1804.

-3 Lepre L, Costa G, Baldini D, et al: Emergency presentation of cystic lymphangioma of the colon: a case report and literature review. Int J Surg Case Rep 2016;24:162-165.

4 Kulkarni J, Bhat N, Pai SA: Cystic lymphangioma of the colon. Indian J Gastroenterol 2009;28:197.

5 Sato K, Maekawa T, Yabuki K, et al: Cystic lymphangiomas of the colon. J Gastroenterol 1999;34:520524.

6 Young TH, Ho AS, Tang HS, Hsu CT, Lee HS, Chao YC: Cystic lymphangioma of the transverse colon: report of a case and review of the literature. Abdom Imaging 1996;21:415-417.

7 Kim TO, Lee JH, Kim GH, et al: Adult intussusception caused by cystic lymphangioma of the colon: a rare case report. World J Gastroenterol 2006;12:2130-2132.

8 Matsuba Y, Mizuiri H, Murata T, Niimi K: Adult intussusception due to lymphangioma of the colon. J Gastroenterol 2003;38:181-185.

-9 Kochman ML, Wiersema MJ, Hawes RH, Canal D, Wiersema L: Preoperative diagnosis of cystic lymphangioma of the colon by endoscopic ultrasound. Gastrointest Endosc 1997;45:204-206.

10 Irisawa A, Bhutani MS: Cystic lymphangioma of the colon: endosonographic diagnosis with throughthe-scope catheter miniprobe and determination of further management. Report of a case. Dis Colon Rectum 2001;44:1040-1042.

11 Hizawa K, Aoyagi K, Kurahara K, et al: Gastrointestinal lymphangioma: endosonographic demonstration and endoscopic removal. Gastrointest Endosc 1996;43:620-624.

12 Ajiki T, Nakamura T, Kubota S, Kim YS, Kuroda Y: Successful endoscopic treatment of colon lymphangioma with a ligating device. Gastrointest Endosc 2000;52:800-802. 


\section{Case Reports in Gastroenterology}

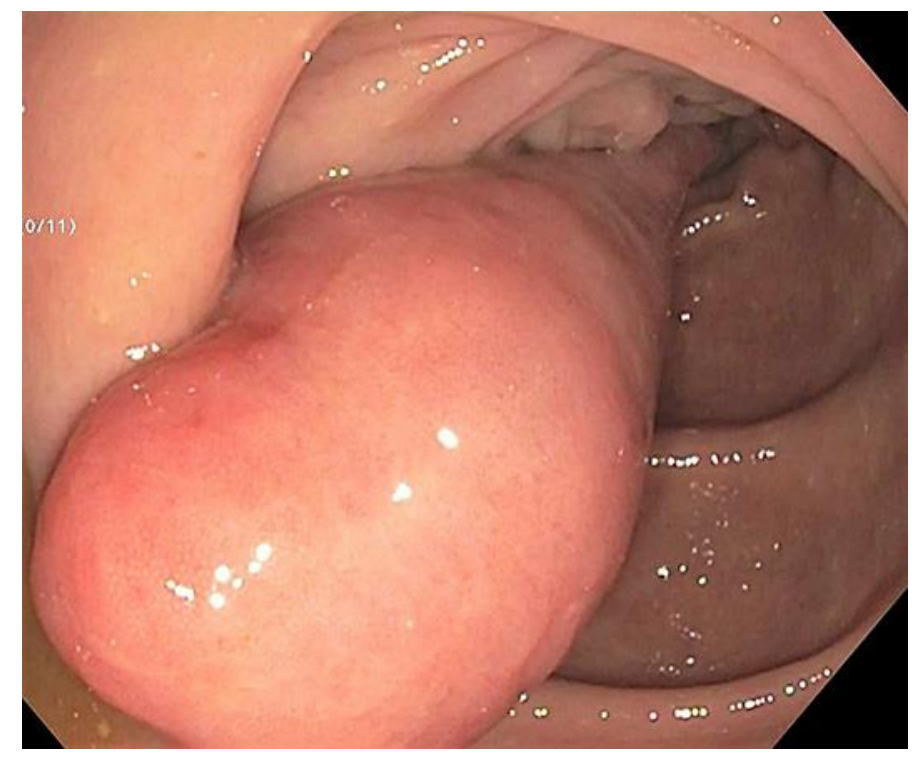

Fig. 1. Peduculated lesion in the ascending colon.

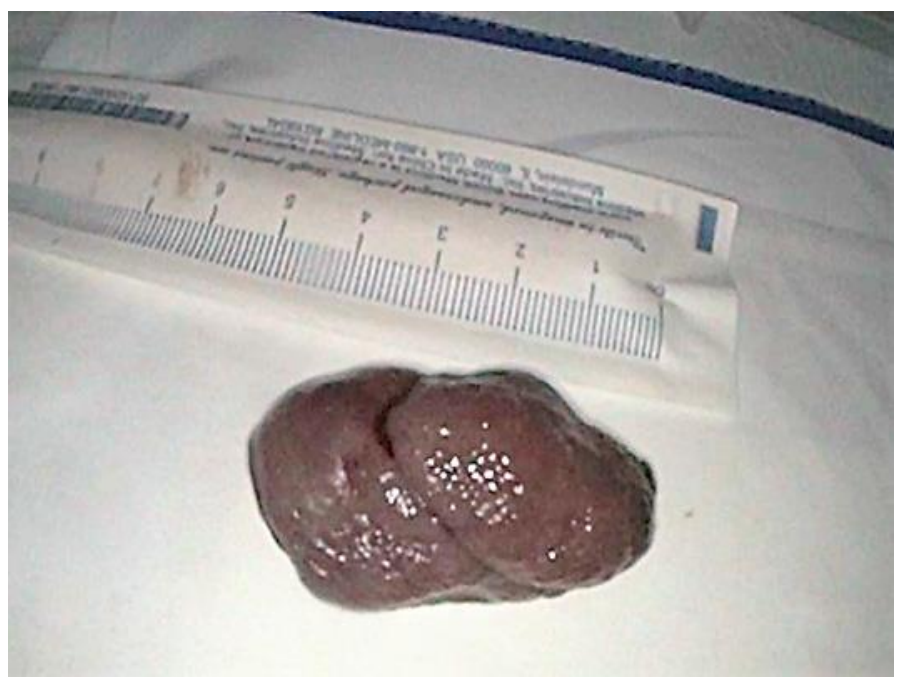

Fig. 2. Gross morphology of the endoscopically resected lesion.

Badipatla et al.: Cystic Lymphangioma of the Colon: Endoscopic Removal beyond the Frontiers of Size www.karger.com/crg 


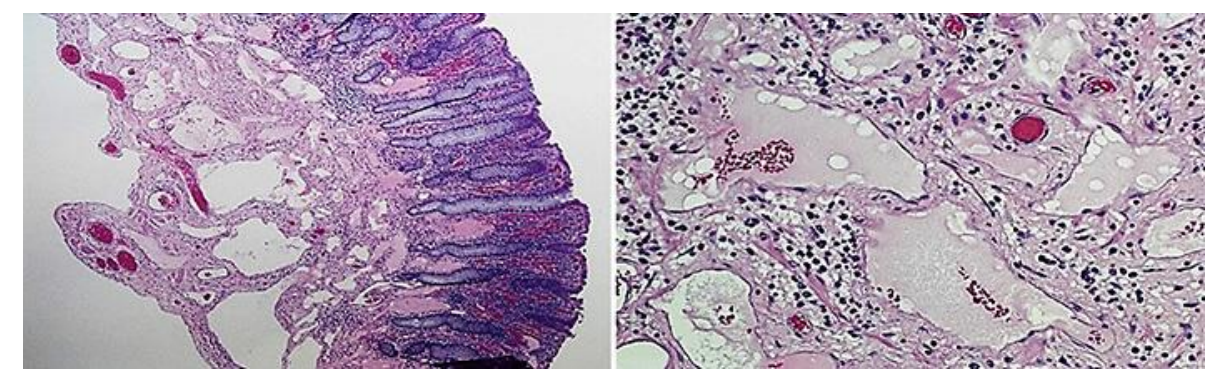

Fig. 3. Cystic lymphangioma of the colon. Hematoxylin and eosin staining under high magnification showing dilated channels lined by endothelial cells containing lymph nodes. The stroma contains fibrocollagenous tissue and scant cellular infiltrate $(\times 100$ magnification).

Badipatla et al.: Cystic Lymphangioma of the Colon: Endoscopic Removal beyond the Frontiers of Size 